Mike, F., Kızılkaya, O. / Journal of Yasar University, 2021, 16/61, 298-309

\title{
Kişi Başına Enerji Tüketiminin Yakınsaması: OECD Ülkeleri İçin Ampirik Bir Analiz ${ }^{1}$
}

\section{Convergence of Per Capita Energy Consumption: An Empirical Analysis For OECD Countries}

Faruk MIKKE, Hakkari Üniversitesi, Türkiye, farukmike@hakkari.edu.tr Orcid No:0000-0002-9194-1679

Oktay KIZILKAYA, Malatya Turgut Özal Üniversitesi, Türkiye, oktay.kizilkaya@ozal.edu.tr Orcid No: 0000-0002-3412-5616

Öz: Enerji tüketimi/kullanımı, günümüz üretim faaliyetlerinin vazgeçilmez bir unsuru olarak kabul edilmekte ve toplumların yaşam kalitesini belirleyen önemli bir parametre olarak nitelendirilmektedir. Enerji tüketiminin yakınsamasl, sürdürülebilir ekonomik büyüme ve karbondioksit emisyonunu engelleme konularında oldukça önemli politika önerilerine sahiptir. Bu anlamda bu çalışmada OECD ülkeleri arasında kişi başına enerji tüketiminin yakınsama özelliği gösterip göstermediği araştırllmaktadır. Analizler 1965-2019 dönemleri için hem keskin hem de yumuşak ve pürüzsüz kırılmaları dikkate alan panel durağanlık testi ile gerçekleştirilmiştir. Elde edilen bulgular 18 ülke için kişi başına enerji tüketimi serisinin durağan olduğunu ve yakınsama hipotezinin bu ülkeler için geçerli olduğunu ortaya koymaktadır. Bu durumun OECD ülkelerinde girişilen enerji verimliliğindeki artış, enerji yoğunluğundaki azalma ve karbondioksit emisyonlarını azaltma çabalarından kaynaklandığ düşünülmektedir.

Anahtar Sözcükler: Enerji Tüketimi, Yakınsama, Dură̆anlık Testi

JEL Sinıflandırması: O13, Q40, C23

Abstract: Energy consumption/usage is considered as an indispensable element of today's production activities and determines the life quality of the societies. The issue of energy convergence is important because it has implications for sustainable economic growth and efforts to curtail carbon dioxide emissions. In this sense, this study empirically examines the convergence of per capita energy consumption among OECD countries. The analyses are carried out using panel stationarity test with sharp and smooth breaks for the period 1965-2019. The findings reveal that the per capita energy consumption is stationary and the convergence hypothesis is valid for 18 countries. This is thought to result from the increase in energy efficiency, decrease in energy intensity, and efforts to reduce carbon dioxide emissions in OECD.

Keywords: Energy Consumption, Convergence, Stationarity Test

JEL Classification: O13, Q40, C23

\section{Giriș}

Ekonomik faaliyetlerin iklim değiş̧ikliği üzerindeki olumsuz etkilerine yönelik giderek artan endişeler, son y1llarda çevre ve enerji ekonomisi literatürü üzerinde yoğun bir araştırma sürecinin önünü açmıştır. Bu doğrultuda sera gazı emisyonlarının oluşumunda (ve beraberinde küresel 1sınmanın meydana gelmesinde) en önemli paya sahip olan karbondioksit emisyonlarının temel belirleyicilerine yönelik literatürde önemli bir ampirik araştırma alanının

\footnotetext{
${ }^{1}$ Bu çalışma International Conference on Applied Economy and Finance Extended with Social Science (e-ICOAEF VII) 'da sunulmuş ve genişletilerek makale haline getirilmiş̧ir.
} 
oluştuğu gözlemlenmektedir. Bu çalışmalardan bazıları bölgesel ülke grupları için temel ekonomik göstergeler ile karbondioksit emisyonu arasındaki ilişkiye odaklanmaktayken ${ }^{2}$, diğer bazıları ise bireysel ülkeler için söz konusu ilişkiyi araştırmaya yönelmişlerdir. ${ }^{3}$

Karbondioksit emisyonlarının artmasına ve beraberinde çevre kirliliğinin meydana gelmesine neden olan faktörlerin başında ise hiç kuşkusuz fosil yakıt kullanımına bağlı olarak ekonomik karar birimlerinin kullanımına sunulan enerji arzı gelmektedir. Enerji tüketimi temel olarak insan hayatına doğrudan etki eden olumlu hizmetleri sayesinde (ulaşım, iletişim, isınma vb.) sosyal ve ekonomik refahın artmasına katkı sağlamakta ve beraberinde ülkelerin sürdürülebilir kalkınma politikası hedeflerini gerçekleştirebilmelerine imkan tanımaktadır (Le, Chang ve Park, 2017: 32). Ancak diğer taraftan literatürde enerji tüketimi/kullanımının çevresel kalite üzerinde olumsuz etkiler meydana getirdiğine yönelik ortak bir yaklaşım da bulunmaktadır. Buna göre özenli bir planlamanın yapılmaması durumunda petrol, doğalgaz ve kömür dahil olmak üzere çeşitli enerji kaynaklarının geliştirilmesi veya kullanılması ekosistemleri bozabilecek etkiler meydana getirebilmektedir (Kaygusuz, 2012: 1118).

Enerji tüketimi ile sürdürülebilir kalkınma arasındaki bu görüş ayrıllğı literatürde enerji tüketimine yönelik çok sayıda ampirik çalışmanın oluşmasına katkı sağlamaktadır. Söz konusu çalışmalardan bir tanesi de kişi başına düşen enerji tüketiminin yakınsama özelliği gösterip göstermediği ile ilgilidir. Enerji tüketiminin yakınsaması, sürdürülebilir ekonomik büyüme ve karbondioksit emisyonunu engelleme konularında oldukça önemli politika önerilerine sahiptir. Özellikle politika yapıcılar için gayrisafi yurtiçi hasıladaki büyümeye bağlı olarak enerji tüketiminin nasıl değiştiğini bilmek oldukça önemlidir. Pek çok ülke hem enerji yoğunluğunu azaltacak hem de enerji verimliliğini artıracak politikalar benimsemektedir. Aynı zamanda karbondioksit emisyonunu azaltmaya yönelik olarak küresel ölçekte ortak bir çaba da bulunmaktadır. Büyüme oranlarının istikrarlı ve enerji yakınsamasının hızlı bir şekilde gerçekleştiği ülkelerde, enerji tüketimindeki artışları engelleyebilecek etkin politikalar uygulanabilmektedir. $\mathrm{Bu}$ nedenle ülkeler arasında kişi başına enerji tüketimindeki eşitsizliklerin azalması, bu tür politikaların başarılı olmasına önemli katkılar sağlamaktadır (Mishra ve Smyth, 2014: 180).

$\mathrm{Bu}$ doğrultuda bu çalışma kişi başına enerji tüketiminin yakınsama özelliğini 31 OECD ülkesi için 1965-2019 dönemi yıllık veriler kullanılarak incelemeyi amaçlamaktadır. Analizler

\footnotetext{
${ }^{2}$ Bölgesel ülke grupları için ampirik analiz gerçekleştiren bazı çalışmalar şu şekildedir: Al-mulali (2011) - MENA ülkelerini; Al-mulali, Tang ve Ozturk (2015) - Latin Amerika ve Karayip ülkelerini; Baek (2016) - Körfez İşbirliği Konseyi ülkeleri; ve Shahbaz, Balsalobre-Lorente ve Sinha (2019) - Orta Doğu ve Kuzey Afrika ülkeleri.

${ }^{3}$ Bireysel ülke analizlerine odaklanan bazı çalışmalar ise şu şekildedir: Ang (2007) - Fransa; Halicioglu (2009) - Türkiye; Jalil ve Feridun (2011) - Çin; Boutabba (2014) - Hindistan; Farhani ve Ozturk (2015) - Tunus; ve Tang ve Tan (2015) - Vietnam.
} 
Li, Ranjbar ve Chang (2015) tarafından geliştirilen ve ayrıca hem keskin hem de yumuşak ve pürüzsüz kırılmaları dikkate alan panel durağanlık testi ile gerçekleştirilecektir. Meng, Payne ve Lee (2013)'in çalışmasından farklı olarak bu çalışma, daha fazla sayıda OECD ülkesini analizlere dahil etmektedir. Ayrıca yapısal kırılmaları dikkate alan panel durağanlık testi, yakınsama hipotezini değerlendirmek anlamında enerji tüketimine ilişkin verilere ait hem kesitsel hem de zaman serisi bilgilerinden yararlanma avantajına sahiptir.

Çalışmanın planlaması sırasıyla şu şekildedir. İkinci bölümde yakınsama hipotezinin enerji ekonomisi literatüründeki uygulamalarına yer verilmektedir. Üçüncü bölüm, veri seti ve ekonometrik metodolojiden oluşmaktadır. Dördüncü bölümde ampirik bulgular tartışılmaktadır. Çalışma sonuç ve değerlendirmenin yer aldığı beşinci ve son bölüm ile tamamlanmaktadır.

\section{Literatür Taraması}

Yakınsama hipotezinin enerji ekonomisi literatürü içerisindeki uygulama alanı, büyük oranda karbondioksit emisyonu ve/veya enerji yoğunluğu değişkenleri üzerine odaklanmakta ve söz konusu serilerin farklı metodolojik yaklaşımlar ( $\beta$-yakınsaması, $\sigma$-yakınsaması, stokastik yakınsama vb.) ile test edilmesine dayanmaktadır. Bu çalışmalardan Aldy (2006), Chang ve Lee (2008), Barassi, Cole ve Elliott (2011), Wang, Zhang, Huang ve Cai (2014), Lin, InglesiLotz ve Chang (2018) ve Churchill, Inekwe ve Ivanovski (2020) karbondioksit emisyonu değişkeni için yakınsama özelliğini araştırmaktayken, Markandya, Pedroso-Galinato ve Streimikiene (2006), Liddle (2010), Mulder ve De Groot (2012), Karimu, Brännlund, Lundgren ve Söderholm (2017) ve Bulut ve Durusu-Ciftci (2018) ise enerji yoğunluğu değişkeni için yakınsama hipotezinin geçerliliğine odaklanmaktadır.

Enerji tüketimi değişkeni ile ilgili olarak ise uluslararası literatür genel olarak enerji tüketiminin entegrasyon özellikleri üzerinde gelişim göstermektedir. Bu çalışmalardan Chen ve Lee (2007), Narayan ve Smyth (2007), Aslan ve Kum (2011), Hasanov ve Telatar (2011), Bolat, Belke ve Celik (2013), Ozcan ve Ozturk (2016) ve Erdogan, Akalin ve Oypan (2020) birim kök testleri vasıtasıyla enerji tüketimi serilerinin durağanlık özelliklerini ortaya koymayı amaçlamışlardır. Enerji tüketiminin veya üretiminin durağanlık özelliğini araştıran bu çalışmaların temel amacı, şokların kalıcı veya geçici etkilere sahip olup olmadıklarını açıklamaktır. Bu sayede enerji ile ilgili uygulanan politikaların kalıcı etkiler meydana getirip getirmediği belirlenebilmekte, enerji sektöründeki şokların diğer sektörlere olan etkileri açıklanabilmekte ve gelecekteki enerji tüketimi ve üretiminin tahmini ve modellenmesine katk1 sağlamaktadır (Meng vd., 2013: 537). 
Ancak son zamanlarda kişi başına düşen enerji tüketiminin yakınsama özelliğini araştırmaya yönelen artan sayıda çalışmanın da literatürde yer aldığı gözlemlenmektedir. $\mathrm{Bu}$ çalışmalardan Meng vd. (2013), kişi başına enerji kullanımının yakınsama özelliğini 25 OECD ülkesi için 1960-2010 dönemleri arasında incelemiştir. Yazarlar çalışmalarında yapısal kırılmaları dikkate almayan (ADF, LM ve RALS-LM), tek yapısal kırılmayı dikkate alan (LM ve RALS-LM) ve iki yapısal kırılmayı dikkate alan (LM ve RALS-LM) üç farklı birim kök testine yer vermişlerdir. Yapısal kırılmaları dikkate almayan ADF birim kök testi bulguları 7, LM birim kök testi bulguları 3 ve RALS-LM birim kök testi bulguları ise 8 ülke için yakınsama hipotezinin geçerliliğini ortaya koymaktadır. Diğer taraftan tek yapısal kırılmayı dikkate alan LM birim kök testi bulguları 8 ve RALS-LM birim kök testi bulguları ise 12 ülke için yakınsama hipotezini doğrulamaktadır. Son olarak iki yapısal kırılmaya izin veren LM ve RALS-LM birim kök test bulguları ise sırasıyla 19 ve 17 ülke için kişi başına enerji tüketiminin yakınsama özelliğini ortaya koymaktadır. Yazarlar çalışmalarında yapısal kırılmaları dikkate almanın enerji tüketimi serilerini daha fazla oranda durağan hale getirdiğine ve bu durumun OECD ülkeleri arasında kişi başına enerji tüketiminin yakınsamasına katkı sağladığına dikkat çekmektedir.

Mishra ve Smyth (2014), kişi başına enerji tüketiminin yakınsamasını ASEAN ülkeleri için 1971-2011 dönemleri doğrultusunda panel KPSS durağanlık ve yapısal kırılmaları dikkate alan panel LM birim kök testleri ile incelemiştir. Beş yapısal kırılmaya kadar izin veren panel KPSS durağanlık testi bulguları, bireysel ülke analizleri içerisinde sadece Filipinler için yakınsama boş hipotezini reddetmektedir. Ülke grupları bakımından (ASEAN-3, ASEAN-4, ASEAN-5 ve ASEAN-8) incelendiğinde ise panel KPSS durağanlık testi sonuçları özellikle ASEAN-5 ülkeleri için yakınsama boş hipotezinin reddedememekte ve bu ülke grubu için yakınsama hipotezinin geçerli olduğunu ortaya koymaktadır. Diğer taraftan bir ve iki kırılmaya izin veren panel LM birim kök testinden elde edilen bulgular, ASEAN-4 ve ASEAN-5 ülkeleri için yakınsama boş hipotezini reddetmekte ve benzer şekilde yakınsama hipotezinin geçerliliğini doğrulamaktadır.

Fallahi ve Voia (2015), diğer çalışmalardan farklı olarak kişi başına enerji tüketiminin yakınsama özelliğini birim kök analizleri yerine alt örneklem güven aralıkları ile araştırmıştır. Yazarlar 25 OECD ülkesi için 1960-2012 dönemlerini dahil ettikleri çalışmalarında 13 ülke için yakınsama hipotezinin geçerli olduğu bulgularına ulaşmışlardır. $\mathrm{Bu}$ ülkeler sırasıyla Avustralya, Avusturya, Belçika, Danimarka, Finlandiya, Hollanda, İspanya, İsviçre, İtalya, Japonya, Lüksemburg, Norveç ve Yunanistan'dan oluşmaktadır.

Hao, Wang ve Zhang (2015), kişi başına enerji tüketiminin yakınsamasını Çin'e ait 29 bölge 
için 1985-2012 dönemleri doğrultusunda statik ve dinamik regresyon yöntemleri aracıllığıyla incelemiştir. Elde edilen bulgular söz konusu bölgeler arasında enerji tüketimi için yakınsama hipotezinin geçerli olduğunu ortaya koymaktadır. Çalışmada ayrıca 1996 yılı önemli bir kırılma tarihi olarak belirlenmiştir. Buna göre kişi başına enerji tüketimi büyüme oranı 1996 yılından sonra, önceki döneme göre daha büyükken, yakınsama hızının görece daha düşük olduğu tespit edilmiştir.

Fallahi (2017), kişi başına enerji tüketiminin yakınsama özelliğini 109 ülke için 1971-2013 dönemleri doğrultusunda alt örneklem güven aralıkları ile incelemiştir. Çalışmada tüm örneklem grubuna ait bulguların yanı sıra 7 alt ülke grubu (Asya ve Okyanusya, Afrika, Amerika, Avrupa ve Orta Doğu bölgelerine ait ülkeler ile OECD ve OPEC ülke grupları) için de analizler gerçekleştirilmiştir. Elde edilen bulgular hem tüm örneklem grubu hem de alt ülke grubu ülkeler için yakınsama hipotezinin geçerli olduğunu ortaya koymaktadır.

Le, Chang ve Park (2017), kişi başına enerji ve elektrik kullanımının yakınsama özelliğini APEC-12 ve APEC-19 ülke grupları için 1989-2012 dönemleri doğrultusunda geleneksel panel birim kök ve Fourier fonksiyonlu Panel KSS birim kök testleri ile incelemiştir. Geleneksel birim kök testinden elde edilen bulgular, APEC ülkelerinin yaşam standartlarındaki artışa bağlı olarak, tüm ülkeler için kişi başına enerji ve elektrik kullanımı değişkenlerinin yakınsama özelliği gösterdiğini ortaya koymaktadır. Diğer taraftan Fourier Panel KSS birim kök testi sonuçları ise 19 APEC ülkesinden 15'i için enerji tüketiminin, 17'si için ise elektrik tüketiminin yakınsama özelliği gösterdiğine işaret etmektedir.

Liu ve Lee (2020), enerji kullanımı/tüketiminin yakınsama özelliğini 107 ülke için 19712014 dönemleri doğrultusunda geleneksel zaman serisi birim kök (ADF, PP ve KPSS), geleneksel panel birim kök (LLC, Breitung, IPS, ADF-Fisher ve PP-Fisher) ve Fourier fonksiyonlu Panel KSS birim kök testleri ile incelemişlerdir. Çalışmadan elde edilen temel bulgular sırasıyla şu şekildedir: (i) Ele alınan dönem süresince 10 ülkeden 7'sinde yakınsama özelliği gözlemlenmekte ve ülkeler arasında güçlü bir ayrışma bulunmamaktadır. (ii) Yüksek gelir ve üst-orta gelir grubu ülkeler, düşük-orta gelir ve düşük gelir grubu ülkelerden daha önce yakınsama özellikleri göstermektedir. (iii) Enerji ihracatı yapan ülkeler, enerji ithalatı yapan ülkelerden daha önce yakınsama özelliği göstermektedir. (iv) Kişi başına düşen gayrisafi hasıla, sanayileşme düzeyi ve bölge, yakınsama üzerinde oldukça önemli etkilere sahiptir.

\section{Veri Seti ve Metodoloji}

Bu çalışmada 1965-2019 dönemi yıllık veriler kullanılarak OECD ülkeleri için kişi başına enerji tüketiminin yakınsama özelliği gösterip göstermediği araştırılmaktadır. Bu doğrultuda 
veri kısıtı bulunmayan 31 OECD ülkesi analizlere dahil edilmiştir. Çalışmada kişi başına düşen enerji tüketimi veri seti kullanılmıştır. Analizlerde kullanılan veriler BP Statistical Review of World Energy (Haziran 2020)'den derlenmiştir.

Kişi başına enerji tüketiminin yakınsama özelliği araştırılırken, nispi enerji tüketimi ölçümünden yararlanılmaktadır (Meng vd., 2013; Mishra ve Symth, 2014). Nispi enerji tüketimi yakınsaması Denklem (1)'de yer alan formül aracılığıyla hesaplanmaktadır:

$$
\text { Nispi Enerji Tüketimi } i_{i t}=\frac{\text { Kişi Başına Enerji Tüketimi }_{\text {it }}}{\text { Kişi Başına Ortalama OECD Enerji Tüketimi }_{\mathrm{t}}}
$$

\subsection{Li, Ranjbar, Chang (LRC, 2015) Panel Durağanlık Testi}

Li, Ranjbar ve Chang (LRC, 2015) tarafindan geliştirilen panel durağanlık testi, Carrion-i Silvestre, Barrio-Castro ve Lopez-Bazo (CBL, 2005) tarafindan geliştirilen durağanlık testine dayanmakta ve veri yapısındaki keskin ve yumuşak yapısal kırılmaları dikkate almaktadır. CBL testinde, durağanlık boş hipotezi altında oluşturulan veri yaratma süreci aşağıdaki modele dayanmaktadır:

$$
y_{i t}=\alpha+\beta t+\sum_{k=1}^{m} \theta_{i k} D U_{k, t}+\sum_{k=1}^{m} \rho_{i k} D T_{k, t}+\varepsilon_{i t}
$$

Burada $\alpha$ sabiti, $t$ trendi ve $m$ ise uygun kırılma sayısını göstermektedir. CBL testinde kullanılacak test istatistiği Denklem (3) ile verilmiştir:

$$
Z(\lambda)=\frac{\left(\sum_{i=1}^{N} L M\left(\lambda_{i}\right)-N \bar{\mu}_{L M}\right)^{0.5}}{\sigma_{L M}} \rightarrow^{d} N(0,1)
$$

Burada $\operatorname{LM}\left(\lambda_{i}\right)$, Kwiatkowski, Phillips, Schmidt ve Shin (1992) tarafindan önerilen test istatistiğidir. $\bar{\mu}_{L M}$ ve $\sigma_{L M}$ ise $\operatorname{LM}\left(\lambda_{i}\right)$ dağılımının sırasıyla ortalaması ve standart sapmasıdır. LRC testinde, yumuşak kırılmaları modellemek amacıyla Fourier yapı modele dahil edilmektedir:

$$
y_{t}=\alpha+\beta t+\sum_{i=1}^{m+1} \theta_{i} D U_{i, t}+\sum_{i=1}^{m+1} \rho_{i} D T_{i, t}+\sum_{k=1}^{n} \gamma_{1, k} \sin \left(\frac{2 \pi k t}{T}\right)+\sum_{k=1}^{n} \gamma_{2, k} \cos \left(\frac{2 \pi k t}{T}\right)+\varepsilon_{t}
$$

Burada $\mathrm{k}$ frekans sayısını, $\mathrm{t}$ trend terimini ve $\mathrm{T}$ ise örneklem büyüklüğünü göstermektedir. Denklem (4)'te keskin yapısal kırılmaları yakalamak için kullanılan DU ve DT kukla değişkenleri aşağıdaki şekilde tanımlanmaktadır:

$$
\begin{gathered}
D U_{k, t}=\left\{\begin{array}{cr}
1 & \text { Ĕger } T B_{k-1}<t<T B_{k} \text { ise } \\
0 & \text { diğer durumlarda }
\end{array}\right. \\
D T_{k, t}=\left\{\begin{array}{cr}
t-T B_{k-1} & \text { Ĕger } T B_{k-1}<t<T B_{k} \text { ise } \\
0 & \text { diğer durumlarda }
\end{array}\right.
\end{gathered}
$$


Enders ve Lee (2012), serbestlik derecesini azaltmak ve aşırı uyum problemini önlemek için $\mathrm{n}=1$ alınmasının faydalı olduğunu ifade etmişlerdir. Bu doğrultuda n=1 kısıtı altında Denklem (4) yeniden yazılabilmektedir:

$$
y_{t}=\alpha+\beta t+\sum_{i=1}^{m+1} \theta_{i} D U_{i, t}+\sum_{i=1}^{m+1} \rho_{i} D T_{i, t}+\gamma_{1} \sin \left(\frac{2 \pi k t}{T}\right)+\gamma_{2} \cos \left(\frac{2 \pi k t}{T}\right)+\varepsilon_{t}
$$

Denklem (7)'nin tahmini için Li vd. (2015) iki aşamalı bir tahmin prosedürü önermişlerdir. İlk aşamada optimum kırılma sayısı $m$ ve optimum frekans sayısı $k^{*}$ belirlenmektedir. Li vd. (2015), k’nın maksimum değerini 7 olarak belirlemişlerdir. Bütün frekans değerleri için Bai ve Perron (1998) tarafından önerilen yöntem kullanarak Denklem (7) tahmin edilmektedir. Kalıntı kareler toplamının minimum olduğu frekans değeri uygun frekans değeri $\left(\mathrm{k}^{*}\right)$ değeri olarak belirlenir. Ardından $\mathrm{k}^{*}$ frekans değeri kullanılarak model yeniden tahmin edilmekte ve optimum kırılma sayısı ve konumu belirlenmektedir.

İkinci aşamada ise Denklem (7) için doğrusal olmayan bileşenin yokluğu yani trigonometrik terimlerin anlamlılığı test edilmektedir. Bu amaçla, Becker, Enders ve Lee (2006) tarafindan önerilen F testi kullanılmaktadır:

$$
F\left(k^{*}\right)=\frac{\left(S S R_{0}-S S R_{1}\left(k^{*}\right)\right) / 2}{S S R_{1}\left(k^{*}\right) /(T-q)}
$$

Burada $S_{S} R_{1}\left(k^{*}\right)$, Denklem (7)'den elde edilen kalıntı kareler toplamını, $S S R_{0}$, trigonometrik terimler olmadan elde edilen kalıntı kareler toplamını, q ise regresörlerin sayısını ifade etmektedir.

\section{Ampirik Sonuçlar}

$\mathrm{Bu}$ çalışmada, kişi başına enerji tüketiminin yakınsama özelliği gösterip göstermediği, Li vd. (2015) tarafında geliştirilen kırılmalı Fourier panel durağanlık testi ile analiz edilmiştir. Tablo 1 'de Panel A, yatay kesit bağımlılı̆̆ı testi sonucunu ve panelin geneli için durağanlık testi sonucunu içermektedir. Panel B'de ise her bir ülkeye ait durağanlık testi sonuçları yer almaktadır. Elde edilen durağanlık testi sonuçları Tablo 1'de yer almaktadır. 
Tablo 1. Kurılmalı Fourier Panel Durağanlık Testi Sonuçları

\begin{tabular}{|c|c|c|}
\hline \multicolumn{3}{|c|}{ Panel A: Panel Pesaran vd. (2008) ve Panel Durağanlık Testi } \\
\hline \multirow{2}{*}{$\begin{array}{l}\text { Panel A: Panel Pesaran } \\
\text { Pesaran vd. (2008) Yatay Kesit Bağımlılığ } \\
\text { Testi }\end{array}$} & Test İstatistiği & p-değeri \\
\hline & 21.533 & 0.000 \\
\hline Panel Durağanlık Testi & Test İstatistiği & p-değeri \\
\hline Homojen Panel KPSS İstatistiği & -3.261 & 0.999 \\
\hline Hetorojen Panel KPSS İstatistiği & -1.926 & 0.972 \\
\hline
\end{tabular}

\begin{tabular}{|c|c|c|c|c|c|}
\hline \multicolumn{6}{|c|}{ Panel B: Birimlerin Durağanlık Testi Sonuçları } \\
\hline Ülkeler & Barlett & $\begin{array}{c}\text { Kritik Değerler } \\
(\% 5)\end{array}$ & Ülkeler & Barlett & $\begin{array}{c}\text { Kritik Değerler } \\
(\% 5)\end{array}$ \\
\hline Avusturya & 0.312 & 0.067 & Japonya & $0.072 *$ & 0.137 \\
\hline Avustralya & 0.405 & 0.068 & Lüksemburg & $0.199 *$ & 0.279 \\
\hline Belçika & $0.072 *$ & 0.138 & Meksika & 0.072 & 0.071 \\
\hline Kanada & $0.019 *$ & 0.070 & Yeni Zelanda & 0.075 & 0.074 \\
\hline Şili & $0.075^{*}$ & 0.082 & Norveç & 0.221 & 0.091 \\
\hline Çekya & $0.118^{*}$ & 0.133 & Polonya & $0.064 *$ & 0.091 \\
\hline Danimarka & $0.093 *$ & 0.098 & Portekiz & 0.182 & 0.075 \\
\hline Finlandiya & 0.084 & 0.070 & Slovakya & 0.144 & 0.072 \\
\hline Fransa & 0.152 & 0.124 & Güney Kore & 0.086 & 0.083 \\
\hline Almanya & $0.072 *$ & 0.078 & İspanya & 0.144 & 0.079 \\
\hline Yunanistan & 0.564 & 0.123 & İsveç & $0.075^{*}$ & 0.235 \\
\hline Macaristan & $0.059 *$ & 0.083 & İsviçre & $0.033 *$ & 0.173 \\
\hline İzlanda & 0.110 & 0.055 & Türkiye & $0.111^{*}$ & 0.120 \\
\hline İrlanda & $0.103^{*}$ & 0.109 & Birleşik Krallık & $0.209 *$ & 0.210 \\
\hline İsrail & $0.056^{*}$ & 0.097 & $\mathrm{ABD}$ & $0.077 *$ & 0.108 \\
\hline İtalya & $0.043 *$ & 0.245 & & & \\
\hline
\end{tabular}

Not: *, \% 5 düzeyinde durağanlığı göstermektedir.

Çalışmada durağanlık sınaması yapılmadan önce birimler arasındaki yatay kesit bağımlılığın varlığı test edilmiştir. Buna göre, yatay kesit bağımlılığı test istatistiği 21.553 ve olasılık değeri ise 0.000 olarak elde edilmiştir. Bu durum yatay kesit bağımlığının olmadığını ifade eden boş hipotezin reddedildiği anlamına gelmektedir. Diğer bir ifadeyle Pesaran, Ullah ve Yagamata (2008) tarafından geliştirilen yatay kesit bağımlılı̆̆ testi sonucu birimler arasında yatay kesit bağımlılığının bulunduğuna işaret etmektedir. Bu doğrultuda verilerin durağanlık sınamalarında yatay kesit bağımlılı̆ğnı dikkate alan testlerin kullanılması gerekmektedir. Li vd. (2015) tarafından geliştirilen panel durağanlık testinde yatay kesit bağımlılığının dikkate alınması için kritik değerlerin elde edilmesinde Maddala ve Wu (1999) tarafindan önerilen bootstrap yöntemi kullanılmaktadır. Panelin geneli için elde edilen durağanlık sınaması sonucuna göre OECD ülkelerinde kişi başına nispi enerji tüketiminin durağanlığını ifade eden boş hipotez reddedilememekte ve panelin durağan olduğuna karar verilmektedir. Diğer taraftan bireysel durağanlık test sonuçları ise 18 ülke (Belçika, Kanada, Şili, Çekya, Danimarka, Almanya, Macaristan, İrlanda, İsrail, İtalya, Japonya, Lüksemburg, Polonya, İsveç, İsviçre, Türkiye, Birleşik Krallık ve ABD) için kişi başına enerji tüketimi serisinin durağan olduğunu ve yakınsama hipotezinin bu ülkeler için geçerli olduğunu ortaya koymaktadır. 
Tablo 2. Fourier Fonksiyonu için Uygun Frekanslar ve F İstatistikleri

\begin{tabular}{lccclccc}
\hline \multicolumn{1}{c}{ Ülkeler } & $k^{*}$ & $\begin{array}{c}\text { F- } \\
\text { İstatistiği }\end{array}$ & $\begin{array}{c}\text { Kritik } \\
\text { Değerler (\%5) }\end{array}$ & Ülkeler & $k^{*}$ & $\begin{array}{c}\text { F- } \\
\text { İstatistiği }\end{array}$ & $\begin{array}{c}\text { Kritik } \\
\text { Değerler (\%5) }\end{array}$ \\
\hline Avusturya & 1 & 47.06 & 3.29 & Japonya & 4 & 4.28 & 3.09 \\
Avustralya & 1 & 123.28 & 3.34 & Lüksemburg & 4 & 24.40 & 3.18 \\
Belçika & 2 & 9.42 & 3.12 & Meksika & 1 & 45.09 & 3.34 \\
Kanada & 1 & 37.92 & 3.34 & Yeni Zelanda & 3 & 3.35 & 3.18 \\
Sili & 1 & 75.93 & 3.17 & Norveç & 2 & 5.67 & 3.15 \\
Çekya & 2 & 12.78 & 3.12 & Polonya & 2 & 37.27 & 3.17 \\
Danimarka & 2 & 31.29 & 3.13 & Portekiz & 4 & 25.38 & 3.11 \\
Finlandiya & 1 & 29.47 & 3.26 & Slovakya & 3 & 7.21 & 3.19 \\
Fransa & 1 & 224.75 & 3.15 & Güney Kore & 3 & 27.26 & 3.21 \\
Almanya & 2 & 61.76 & 3.15 & İspanya & 1 & 39.97 & 3.14 \\
Yunanistan & 2 & 23.95 & 3.11 & İsveç & 2 & 62.00 & 3.19 \\
Macaristan & 5 & 21.11 & 3.29 & İsviçre & 1 & 88.27 & 3.12 \\
İzlanda & 1 & 53.02 & 3.26 & Türkiye & 3 & 45.13 & 3.17 \\
İrlanda & 3 & 20.48 & 3.18 & Birleşik Krall1k & 5 & 8.68 & 3.26 \\
İ́srail & 1 & 55.60 & 3.17 & ABD & 3 & 17.92 & 3.21 \\
İtalya & 2 & 52.32 & 3.24 & & & & \\
\hline Not: & & & & & & \\
\hline
\end{tabular}

Not: *, \% 5 düzeyinde anlamlılı̆̆ göstermektedir.

Analizde kullanılan her bir ülkeye ait Fourier fonksiyonu için hesaplanan uygun frekans sayıları ve F istatistikleri sonuçları Tablo 2'de yer almaktadır. Tablo 2 incelendiğinde, bütün ülkeler için elde edilen F-istatistikleri \% 5 kritik değerden büyük olduğundan doğrusal olmayan trendin anlamsız olduğunu ifade eden boş hipotez reddedilmektedir. Tablo 3'de çalışmada ele alınan ülkeler için tahmin edilen kırılma tarihleri verilmiştir.

Tablo 3. Ülkeler için Elde Edilen Kırılma Tarihleri

\begin{tabular}{|c|c|c|c|c|c|}
\hline Ülkeler & Karilma 1 & Kurılma 2 & Ülkeler & Karilma 1 & Kirılma 2 \\
\hline Avusturya & 1972 & 1978 & Japonya & 1969 & 1988 \\
\hline Avustralya & 1973 & 1979 & Lüksemburg & 1975 & 2014 \\
\hline Belçika & 1989 & - & Meksika & 1973 & 1979 \\
\hline Kanada & 1973 & 1979 & Yeni Zelanda & 1981 & 1989 \\
\hline Şili & 1990 & 2010 & Norveç & 1980 & 2002 \\
\hline Çekya & 1989 & - & Polonya & 1973 & 1989 \\
\hline Danimarka & 1972 & 1998 & Portekiz & 1977 & 1990 \\
\hline Finlandiya & 1969 & 1978 & Slovakya & 1973 & 1992 \\
\hline Fransa & 1969 & - & Güney Kore & 1979 & 1996 \\
\hline Almanya & 1990 & 2003 & İspanya & 1972 & 1999 \\
\hline Yunanistan & 1970 & 1987 & İsveç & 2001 & 2006 \\
\hline Macaristan & 1976 & 1991 & İsviçre & 1988 & - \\
\hline İzlanda & 1998 & 2007 & Türkiye & 1982 & 2002 \\
\hline İrlanda & 1969 & 1990 & Birleşik Krallık & 1974 & 2007 \\
\hline İsrail & 1984 & 2010 & $\mathrm{ABD}$ & 1979 & 2000 \\
\hline İtalya & 1969 & 1980 & & & \\
\hline
\end{tabular}

Çalışmada kullanılan gözlem sayısı göz önüne alındığında maksimum kırılma sayısı 2 olarak belirlenmiştir. Belçika, Çekya, Fransa ve İsviçre için uygun kırılma sayısı 1 olarak, diğer ülkeler için ise 2 olarak elde edilmiştir. 


\section{Sonuç}

$\mathrm{Bu}$ çalışmada OECD ülkeleri arasında kişi başına enerji tüketiminin yakınsama özelliği gösterip göstermediği Li vd. (2015) tarafından geliştirilen panel durağanlık testi kullanılarak araştırılmaktadır. Li vd. (2015) panel durağanlık testi hem keskin hem de yumuşak ve pürüzsüz kırılmaları dikkate almaktadır. Bu test prosedüründe keskin kırılmalar için kırılma tarihlerinin içsel olarak belirlendiği kukla değişkenler kullanılırken, yumuşak kırılmaları yakalayabilmek için ise Fourier yaklaşımı kullanılmıştır. Panelin geneli için elde edilen durağanlık sınaması sonucuna göre OECD ülkelerinde kişi başına nispi enerji tüketiminin durağanlığını ifade eden boş hipotez reddedilememekte ve panelin durağan olduğuna karar verilmektedir. Diğer taraftan bireysel durağanlık test sonuçları 18 ülke için kişi başına enerji tüketimi serisinin durağan olduğunu ve yakınsama hipotezinin bu ülkeler için geçerli olduğunu ortaya koymaktadır. Elde edilen bulgular bütüncül olarak değerlendirildiğinde, OECD ülkelerinin nispi enerji tüketimlerinin yakınsama özelliği gösterdiği anlaşılmaktadır. Diğer taraftan bireysel ülke grupları açısından değerlendirildiğinde, OECD ülkelerinin yaklaşık \%60'ının nispi enerji tüketimi verisi yakınsama özelliği göstermektedir. Elde edilen bulgular OECD ülkelerinde enerji entegrasyonuna yönelik geliştirilecek politikaların başarılı olabileceğini ortaya koymaktadır. Sonuçlar ayrıca enerji tüketimi düşük seviyede olan ülkelerin, yüksek enerji tüketimine sahip ülkelere yakınsadığını ortaya koymaktadır. OECD ülkelerinde kişi başına nispi enerji tüketiminin yakınsama özelliği göstermesi, söz konusu ülkelerdeki; enerji verimliliğindeki artış, enerji yoğunluğundaki azalma, enerjiye kolay ulaşım ve karbondioksit emisyonunu azaltma çabalarından kaynaklandığı düşünülmektedir. Özellikle yenilenebilir enerji kaynakları gibi daha fazla verimlilik tasarrufu sağlayacak politikalar ile sera gazı emisyonlarını azaltmaya yönelik girişimlerin, enerji yakınsamasına daha fazla katkı sağlayacağı düşünülmektedir. Gelecekte farklı ülke grupları veya ekonomik örgütler için benzer konuda çalışmalar gerçekleştirilebilir. 


\section{KAYNAKÇA}

Aldy, J. E. (2006) “Per Capita Carbon Dioxide Emissions: Convergence or Divergence?”, Environmental and Resource Economics, 33(4), 533-555.

Al-Mulali, U. (2011) “Oil Consumption, CO2 Emission and Economic Growth in MENA Countries”, Energy, 36(10), 6165-6171.

Al-Mulali, U., Tang, C. F., \& Ozturk, I. (2015) "Estimating the Environment Kuznets Curve Hypothesis: Evidence from Latin America and the Caribbean Countries", Renewable and Sustainable Energy Reviews, 50, 918924.

Ang, J. B. (2007) “CO2 Emissions, Energy Consumption, and Output in France”, Energy policy, 35(10), 47724778.

Aslan, A., \& Kum, H. (2011) "The Stationary of Energy Consumption for Turkish Disaggregate Data by Employing Linear and Nonlinear Unit Root Tests", Energy, 36(7), 4256-4258.

Baek, J. (2016) “A New Look at the FDI-Income-Energy-Environment Nexus: Dynamic Panel Data Analysis of ASEAN", Energy Policy, 91, 22-27.

Bai, J. \& Perron, P. (1998) "Estimating and Testing Linear Models with Multiple Structural Changes", Econometrica, 66, 47-78.

Barassi, M. R., Cole, M. A., \& Elliott, R. J. (2011) "The Stochastic Convergence of CO 2 Emissions: A Long Memory Approach", Environmental and Resource Economics, 49(3), 367-385.

Becker, R., Enders, W., \& Lee, J. (2006) "A Stationarity Test in the Presence of an Unknown Number of Smooth Breaks", Journal of Time Series Analysis, 27(3), 381-409.

Bolat, S., Belke, M., \& Celik, N. (2013) "Mean Reverting Behavior of Energy Consumption: Evidence from Selected MENA Countries", International Journal of Energy Economics and Policy, 3(4), 315.

Boutabba, M. A. (2014) “The Impact of Financial Development, Income, Energy and Trade on Carbon Emissions: Evidence from the Indian Economy”, Economic Modelling, 40, 33-41.

Bulut, U., \& Durusu-Ciftci, D. (2018) "Revisiting Energy İntensity Convergence: New Evidence from OECD Countries”, Environmental Science and Pollution Research, 25(13), 12391-12397.

Carrion- i- Silvestre, J., L., Barrio- Castro, D., \& López- Bazo, E. (2005) "Breaking the Panels: An Application to the GDP Per Capita", The Econometrics Journal, 8(2), 159-175.

Chang, C. P., \& Lee, C. C. (2008) “Are Per Capita Carbon Dioxide Emissions Converging among Industrialized Countries? New Time Series Evidence with Structural Breaks", Environment and Development Economics, 497-515.

Chen, P. F., \& Lee, C. C. (2007) "Is Energy Consumption Per Capita Broken Stationary? New Evidence from Regional-Based Panels", Energy Policy, 35(6), 3526-3540.

Churchill, S. A., Inekwe, J., \& Ivanovski, K. (2020) "Stochastic Convergence in Per Capita CO2 Emissions: Evidence from Emerging Economies, 1921-2014”, Energy Economics, 86, 104659.

Enders, W. \& Lee, J. (2012) “A Unit Root Test Using a Fourier Series to Approximate Smooth Breaks”, Oxford Bulletin of Economics and Statistics, 74(4), 574-599.

Erdogan, S., Akalin, G., \& Oypan, O. (2020) “Are Shocks to Disaggregated Energy Consumption Transitory or Permanent in Turkey? New Evidence from Fourier Panel KPSS Test", Energy, 197, 117174.

Fallahi, F. (2017) "Stochastic Convergence in Per Capita Energy Use in World”, Energy Economics, 65, $228-239$.

Fallahi, F., \& Voia, M. C. (2015) "Convergence and Persistence in Per Capita Energy Use among OECD Countries: Revisited Using Confidence İntervals”, Energy Economics, 52, 246-253.

Farhani, S., \& Ozturk, I. (2015) “Causal Relationship between CO 2 Emissions, Real GDP, Energy Consumption, Financial Development, Trade Openness, and Urbanization in Tunisia", Environmental Science and Pollution Research, 22(20), 15663-15676.

Halicioglu, F. (2009) “An Econometric Study of CO2 Emissions, Energy Consumption, Income and Foreign Trade in Turkey", Energy Policy, 37(3), 1156-1164.

Hao, Y., Wang, S., \& Zhang, Z. Y. (2015) "Examine the Convergence in Per Capita Energy Consumption in China with Breakpoints", Energy Procedia, 75, 2617-2625.

Hasanov, M., \& Telatar, E. (2011) “A Re-Examination of Stationarity of Energy Consumption: Evidence from New Unit Root Tests”, Energy Policy, 39(12), 7726-7738.

Jalil, A., \& Feridun, M. (2011) “The Impact of Growth, Energy and Financial Development on the Environment in China: A Cointegration Analysis”, Energy Economics, 33(2), 284-291.

Karimu, A., Brännlund, R., Lundgren, T., \& Söderholm, P. (2017) "Energy Intensity and Convergence in Swedish Industry: A Combined Econometric and Decomposition Analysis", Energy Economics, 62, 347-356.

Kaygusuz, K. (2012) "Energy for Sustainable Development: A Case of Developing Countries”, Renewable and Sustainable Energy Reviews, 16(2), 1116-1126.

Kwiatkowski, D., Phillips, P. C., Schmidt, P., \& Shin, Y. (1992) "Testing the Null Hypothesis of Stationarity Against the Alternative of a Unit Root: How Sure Are We That Economic Time Series Have a Unit Root? ", Journal of Econometrics, 54(1-3), 159-178. 
Le, T. H., Chang, Y., \& Park, D. (2017) “Energy Demand Convergence in APEC: An Empirical Analysis”, Energy Economics, 65, 32-41.

Li, J. P., Ranjbar, O., \& Chang, T. (2015) "Unemployment Hysteresis in Piigs Countries: A New Test With Both Sharp and Smooth Breaks", The Singapore Economic Review, 60(4) 1-13.

Liddle, B. (2010) "Revisiting World Energy Intensity Convergence for Regional Differences", Applied Energy, 87(10), 3218-3225.

Lin, J., Inglesi-Lotz, R., \& Chang, T. (2018) "Revisiting CO2 Emissions Convergence in G18 Countries”, Energy Sources, Part B: Economics, Planning, and Policy, 13(5), 269-280.

Liu, T. Y., \& Lee, C. C. (2020) "Convergence of the World's Energy Use”, Resource and Energy Economics, 101199.

Maddala, G. S. \& Wu, S. (1999) “A Comparative Study of Unit Roots Tests with Panel Data and A New Simple Test", Oxford Bulletin of Economics and Statistics, 61(S1), 631-652.

Markandya, A., Pedroso-Galinato, S., \& Streimikiene, D. (2006) "Energy Intensity in Transition Economies: Is There Convergence towards the EU Average?", Energy Economics, 28(1), 121-145.

Meng, M., Payne, J. E., \& Lee, J. (2013) "Convergence in Per Capita Energy Use among OECD Countries", Energy Economics, 36, 536-545.

Mishra, V., \& Smyth, R. (2014) "Convergence in Energy Consumption Per Capita among ASEAN Countries",Energy policy, 73, 180-185.

Mulder, P., \& De Groot, H. L. (2012) "Structural Change and Convergence of Energy Intensity across OECD Countries, 1970-2005”, Energy Economics, 34(6), 1910-1921.

Narayan, P. K., \& Smyth, R. (2007) "Are Shocks to Energy Consumption Permanent or Temporary? Evidence from 182 Countries", Energy policy, 35(1), 333-341.

Ozcan, B., \& Ozturk, I. (2016) “A New Approach to Energy Consumption Per Capita Stationarity: Evidence from OECD Countries”, Renewable and Sustainable Energy Reviews, 65, 332-344.

Pesaran, M., H., Ullah, A., \& Yamagata, T. (2008) "A Bias-Adjusted LM Test of Error Cross-Section Independence", Econometrics Journal, 11, 105-127.

Shahbaz, M., Balsalobre-Lorente, D., \& Sinha, A. (2019) "Foreign Direct Investment-CO2 Emissions Nexus in Middle East and North African Countries: Importance of Biomass Energy Consumption", Journal of cleaner production, 217, 603-614.

Tang, C. F., \& Tan, B. W. (2015) "The Impact of Energy Consumption, Income and Foreign Direct İnvestment on Carbon Dioxide Emissions in Vietnam", Energy, 79, 447-454.

Wang, Y., Zhang, P., Huang, D., \& Cai, C. (2014) "Convergence Behavior of Carbon Dioxide Emissions in China”, Economic Modelling, 43, 75-80. 